\title{
Living isolated cells from inner ear vessels: A new approach for studying the regulation of cochlear microcirculation and vascular permeability *
}

\author{
Kerstin Lamm ${ }^{a, b, *}$, Gary Zajic ${ }^{b}$, Jochen Schacht ${ }^{b}$ \\ ${ }^{a}$ Department of Otorhinolaryngology, University Clinic rechts der Isar, Technical University of Munich, Ismaningerstrasse 22, 81675 Munich, FRG \\ ${ }^{\mathrm{b}}$ Kresge Hearing Research Institute, University of Michigan, Ann Arbor, MI, USA
}

Received 9 November 1993; revised 6 September 1994; accepted 14 September 1994

\begin{abstract}
The spiral modiolar artery with its proximal branches and the microvessels in the spiral ligament and the stria vascularis were microdissected from the guinea pig cochlea. After incubation with proteolytic and collagenolytic enzymes the mixed cell suspension was fractionated by gradient centrifugation. The cells migrated according to their buoyant densities into the fractions of $1.04 \mathrm{~g} / \mathrm{ml}$ (endothelial cells), $1.06 \mathrm{~g} / \mathrm{ml}$ (vascular smooth muscle cells obtained from the spiral modiolar artery; strial pericytes) and $1.08 \mathrm{~g} / \mathrm{ml}$ (pericytes obtained from the spiral ligament). To test for viability cells were loaded with a fluorescent vital stain (BCECF-AM); for identification, cell-specific staines were used. Identity of endothelial cells (ECs) was confirmed using acetylated low density lipoprotein fluorescently labeled with dioctadecyl-tetramethyl-indocarbocyanine perchlorate (DiIAc-LDL). Pericytes were identified immunofluorescently using the method according to Nayak et al. (1988). Vascular smooth muscle cells were stained for F-actin with rhodamin-phalloidin.

This in vitro technique may open new approaches to study local factors involved in microcirculation and vessel permeability of various cochlear vascular beds.
\end{abstract}

Keywords: Microcirculation; Cochlea; Cochlear blood flow; Endothelium, vascular; Pericytes; Muscle, smooth, vascular; Cell culture; Guinea pig

\section{Introduction}

The inner ear is unique in the number and the variety of microvascular networks present in its tissues (Smith, 1951 Smith, 1973; Axelsson, 1968 Axelsson and Vertes, 1978; Hawkins, 1968, et al., 1972, 1976; Nomura and Hiraide, 1968; Lawrence, 1970; Lawrence and Clapper, 1973;Wersäll et al., 1973; Kimura and Ota, 1974; Ritter, 1974; Maass, 1982). These networks receive their blood supply from the spiral modiolar artery, which winds behind the bony wall of the cochlear modiolus around the modiolar tissues. This artery gives

\footnotetext{
${ }^{2}$ Presented at the 16th Midwinter Research Meeting, Association for Research in Otolaryngology, St. Petersburg Beach, FL, USA, Feb $7-11,1993$.

* Corresponding author. Department of Otorhinolaryngology, HNO, University Clinic Klinikum rechts der Isar, Technical University of Munich, Ismaningerstrasse 22, 81675 München, FRG. Tel: +49 (089) 4140-4191; Fax: + 49 (089) 4180-5153.
}

off three branches at regular intervals. One branch feeds four independent microvascular networks in the lateral wall tissues: the suprastrial capillaries in the spiral ligament, the strial capillaries, the longitudinal vessels of the spiral prominence and the microvessels of the spiral ligament. The second branch leads toward the parallel capillary networks of the limbus, the tympanic lip (inner spiral 'vessel') and the outer spiral 'vessel' of the basilar membrane. The third branch feeds capillaries within the modiolar tissue: the cochlear plexus (Jahnke, 1980), the spiral ganglion and the auditory nerve. The primary branches coil upon themselves before they penetrate the bony wall of the modiolus to form the 'glomeruli arteriosi' (Schwalbe, 1887), also designated as 'vascular spring coils' (Smith, 1951; Axelsson, 1968) or 'convolutes' (Axelsson, 1968; Ritter, 1974).

The complexity of this vascular network seems reflected in the regulation of cochlear blood flow. Measurements in vivo have established that cochlear blood flow depends on systemic blood pressure and cardiac 
output. However, less is known from in-vivo studies about local factors of vascular control systems in the cochlea as neural, humoral and metabolic, endothelial, and myogenic regulatory mechanisms (for a review see Lamm, 1992). In order to understand molecular mechanisms involved in the complex interplay of intrinsic myogenic vascular tone, vasomotion and permeability within the various cochlear vascular beds we need to approach the subject at the cellular level. So far there has only been one attempt to culture endothelial cells derived from the bovine vascular stria and spiral ligament to examine permeability for horseradish peroxidase (Bowman et al., 1985). Therefore we have now established an isolation procedure for viable single cells from cochlear microvessels of the guinea pig yielding endothelial cells (ECs), pericytes (PCs) and vascular smooth muscle cells (VSMCs).

\section{Materials and methods}

\subsection{Microdissection of cochlear vessels}

Healthy adult pigmented guinea pigs weighing 250 $350 \mathrm{~g}$ were decapitated, after which the temporal bones were rapidly removed and the bulla opened. Temporal bones were then transfered into Hanks' balanced salt solution $\left(137 \mathrm{mM} \mathrm{NaCl}, 5.4 \mathrm{mM} \mathrm{KCl}, 1.25 \mathrm{mM} \mathrm{CaCl}_{2}\right.$,

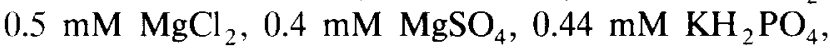
$5.5 \mathrm{mM}$ D-glucose; Gibco, Bethesda, MD) which was buffered with $5 \mathrm{mM}$ sodium HEPES ( $N$-2-hydroxyethylpiperazine- $N$-2-ethane-sulfonic acid) and adjusted to $\mathrm{pH} 7.4$ with $1 \mathrm{~N} \mathrm{NaOH}$ and to $300 \pm 2$ mOsm with $4 \mathrm{~N}$ $\mathrm{NaCl}$. All procedures were carried out at room temperature unless indicated. Under the dissecting microscope, the bony wall of the cochlea was carefully opened at the apex and removed turn by turn. The lateral wall tissues were peeled off and then the vascular stria was separated from the spiral ligament. The samples were transfered into separate microtubes containing $160 \mu \mathrm{l}$ of KELA-medium: $5 \mathrm{ml}$ of $10 \times$ Gibco M 199 with Earle's Salt (Gibco, Bethesda, MD) diluted in $25 \mathrm{ml}$ of 29 mM HEPES (Sigma, St. Louis, MO), supplemented with $0.1 \%$ bovine serum albumin (Lyophilized Powder, Sigma, St. Louis, MO), $10 \%$ fetal calf serum (FCS), penicillin $(10,000 \mathrm{U} / \mathrm{ml})$ and streptomycin $(100 \mu \mathrm{g} / \mathrm{ml})$ and finally adjusted to $\mathrm{pH} 7.4$ and $300 \pm 2$ mOsm. The spiral modiolar artery with its primary branches was approached via the bony modiolus, separated from the modiolar tissue and transfered into a microtube containing KELA-medium.

\subsection{Enzymatic incubation of dissected preparations}

The extracellular matrix of the spiral modiolar artery was digested for $12-16 \mathrm{~h}$ at $37^{\circ} \mathrm{C}$ in KELA-medium additionally containing $2.0 \mathrm{mg} / \mathrm{ml}$ collagenase (type $\mathrm{II}$, Sigma, St. Louis, MO), $1.5 \mathrm{mg} / \mathrm{ml}$ dispase II (Boehringer Mannheim, Indianapolis, IN), $0.4 \mathrm{mg} / \mathrm{ml}$ elastase (Sigma, St. Louis, MO) and $1.0 \mathrm{mg} / \mathrm{ml}$ soybean trypsin-inhibitor (type I-S, Sigma, St. Louis, MO). The tubes were gently agitated in a shaking waterbath to disperse the cells mechanically. The vascular stria and the spiral ligament preparations were similarly incubated for $12 \mathrm{~h}$ in KELA-medium additionally containing $1.5 \mathrm{mg} / \mathrm{ml}$ collagenase/dispase combination (Boehringer Mannheim, Indianapolis, IN). The resulting mixed cell suspensions were washed twice with KELA-medium and once with phosphate-buffered saline (PBS), $\mathrm{pH} 7.4,300 \pm 2$ mOsm. They were then incubated with fluorescently labeled identification markers.

\subsection{Identification of cells (ECs, PCs and VSMCs)}

In order to identify ECs, the cell suspensions obtained from the spiral modiolar artery, vascular stria and spiral ligament were incubated prior to gradient centrifugation for $180 \mathrm{~min}$ at $37^{\circ} \mathrm{C}$ in a humified dark chamber with $50 \mu \mathrm{l}$ of acetylated low density lipoprotein labeled with 1,1'-dioctadecyl-1-3,3,3',3'-tetramethyl-indocarbocyanine perchlorate (DiI-Ac-LDL, Biomed Technologies Inc., Stoughton, MA) per ml KELA-medium.

The presence of VSMCs was established after gradient centrifugation by testing for F-actin with fluorescently labeled phalloidin. Each fraction was incubated with $40 \mu \mathrm{l}$ of saponin (Sigma, St. Louis, MO; 1.0 $\mathrm{mg} / \mathrm{ml}$ KELA-medium) to permeabilize the cells and with $40 \mu \mathrm{l}$ of rhodamine isothiocyanate (RITC) conjugated phalloidin (RITC-phalloidin, Molecular Probes Inc., Eugene, OR; dilutet 1:50 with methanol; 6.0 $\mu \mathrm{l} / \mathrm{ml}$ KELA-medium).

To characterize PCs the immunofluorescence method according to Nayak et al. (1988) was used. Each cell suspension was incubated before gradient centrifugation for $60 \mathrm{~min}$ with the monoclonal antibody 3G5 (kindly provided by Dr. Nayak, Joslin Diabetis Center, Boston, MA) diluted 1:1000 in PBS. This was followed by a second incubation with 1:100 diluted RITC-conjugated goat anti-mouse $\operatorname{IgM}$ (Boehringer Mannheim, Indianapolis, IN) for $60 \mathrm{~min}$ in a humified dark chamber.

\subsection{Staining with BCECF-AM for cell viability}

Cells were stained for viability using $2^{\prime}, 7^{\prime}$-bis-(2carboxyethyl)-5-(and-6)-carboxyfluorescein, acetoxymethyl ester (BCECF-AM, Molecular Probes Inc., Eugene, OR). One-millimolar stock solutions of BCECFAM were prepared in dry dimethyl sulfoxide (DMSO, Sigma, St. Louis, $\mathrm{MO}$ ) and stored at $-20^{\circ} \mathrm{C}$. Final 
solutions were always freshly prepared in KELAmedium at a concentration of $2.5 \mu \mathrm{M} / \mathrm{ml}$. For dye loading, the cell suspensions were incubated for $30 \mathrm{~min}$ in a humified dark chamber, washed two times with KELA-medium and then transfered onto the gradients for centrifugation.

Dual staining with cell identifying reagent and BCECF-AM for viability was performed with PCs only. VSMCs were first stained and scored for viability with BCECF-AM and then permeabilized and stained for F-actin as described above. ECs were singly stained, either with BCECF-AM or with the speicific probe DiI-Ac-LDL.

The percentage of viable VSMCs and PCs after gradient centrifugation was calculated from 5 experiments with each cell type in each of which 100 cells were counted using a hemocytometer. In addition, 3 experiments were performed with BCECF-AM-loaded PCs which had not been immunofluorescently labeled. Since ECs appeared in cell clusters of various size, the percentage of viable clusters was calculated in 5 experiments in each of which 50 clusters were counted.

Mixed cell suspensions were also scored for viability before gradient centrifugation. This analysis was performed in 2 experiments of each of the three cell suspensions obtained from the spiral modiolar artery, spiral ligament and vascular stria.

\subsection{Density gradient centrifugation}

In order to separate ECs, PCs and VSMCs from one another and from cellular debris and nonvascular cells, the mixed cell suspensions were transfered onto preformed gradients. The nontoxic, nonionic, isotonic density gradient medium ( 290 mOsm; $1.15 \mathrm{~g} / \mathrm{ml}$ ) Nycodenz $^{\mathrm{R}}$ (Nycomed Pharma, Oslo, Norway) was diluted by addition of the gradient diluent ( $251 \mathrm{mOsm} ; 1.003$ $\mathrm{g} / \mathrm{ml}$ ) which consisted of $0.75 \% \mathrm{NaCl}$ dissolved in 0.3 $\mathrm{mM} \mathrm{CaNa}{ }_{2}$ EDTA, $5 \mathrm{mM}$ Tris- $\mathrm{HCl}(\mathrm{pH} \mathrm{7.5)}$ and 3.0 $\mathrm{mM} \mathrm{KCl}$ (Ford and Rickwood, 1982; Rickwood et al., 1982). Four-step gradients were formed in $5 \times 20 \mathrm{~mm}$ microtubes by underlayering $40 \mu 1$ each of four solutions of different densities (see results). Continuous gradients were allowed to form by diffusion with tubes laid horizontally for $45 \mathrm{~min}$. Fourty $\mu 1$ of cell suspensions were placed onto the gradient and centrifuged in a swinging bucket rotor for $40 \mathrm{~min}$ at $800 \mathrm{~g}$. Five fractions of $40 \mu$ l each were removed from the top by pipetting and maintained in a saturated humid chamber on micro cover glass slips (thickness $0.13 \mathrm{~mm}$ ) for microscopic observation and photomicrography.

\subsection{Microscopy and photomicrography}

Cells were observed and photographed with an inverted microscope (Leitz Fluovert; Nikon DIAPHO-
TMD) equipped with an epifluorescence system (ArcLamp HBO $100 \mathrm{~W}$; a $450-490 \mathrm{~nm}$ and 515-560 band pass exciter filter set, $510 \mathrm{~nm}$ dichroic mirror, and a $520 \mathrm{~nm}$ barrier filter for excitation and emission, respectively) and Leitz 160/- NPL FLUOTAR 60/1.00 oil immersion objectives. Photomicrographs were taken both as brightfield images on $160 \mathrm{~T}$ Kodak Ektachrome film exposed at 160 ASA and fluorescence photomicrographs on P800/1600 Kodak Ektachrome film exposed at 1600 ASA using two cameras (NIKON F 90; NIKON FG 20).

In order to prevent photobleaching, the excitation irradiance was reduced by a $75 \%$ neutral density filter, and the fraction containing the cells was supplemented with $40 \mu \mathrm{l}$ of $1 \mathrm{mM}$ p-phenylenediamine dihydrochloride (Sigma, St. Louis, MO). Under these conditions, no significant photobleaching was noted with illumination of up to $1 \mathrm{~min}$, sufficient for all observations and photography.

\subsection{Animal welfare}

This study was performed in accordance with the PHS Policy on Human Care and Use of Laboratory Animals, the NIH Guide for the Care and Use of Laboratory Animals, and the Animal Welfare Act (7 U.S.C. et seq.); the animal use protocol was approved by the Institutional Animal Care and Use Committee (IACUC) of the University of Michigan.

\section{Results and discussion}

\subsection{Vascular smooth muscle cells}

Our microdissection technique was successful in preparing the entire spiral modiolar artery with its primary branches, the 'vascular spring coils' of the radiating arterioles. From these preparations, viable single VSMCs with a diamter of 10 to $12 \mu \mathrm{m}$ and viable VSMC-clusters consisting of 3 to about 50 cells were isolated.

Dosis and enzyme mixture used by Droogmans et al. (1987) and Simard (1991) in order to disperse smooth muscle cells from the basilar artery of guinea pigs was modified: DNase was not added to the enzymatic digestion medium since viability of VSMCs isolated from the spiral modiolar artery decreased significantly. Similar, incubation in $\mathrm{Ca}^{2+}$-free medium was avoided so as trypsination. The composition of medium (KELAmedium) was in accordance to Bowman et al. (1985) with some modification: bovine serum albumin and fetal calf serum were supplemented and fungistatic drugs were not added. The KELA-medium was carefully adjusted to $300 \pm 2 \mathrm{mOsm}$ to prevent swelling or shrinking of isolated cells. 

According to observations in fixed tissue specimens using transmission electron microscopy (TEM) the internal wall of the spiral modiolar artery is composed of ECs, covered by an elastic layer and up to three layers of VSMCs with a diameter of about $15 \mu \mathrm{m}$ (Kimura and Ota, 1974). Freshly isolated viable contractile cells as VSMCs tend to round up in the medium and therefore appear somewhat smaller than in situ.

Neither by fluorescence staining nor by morphological features could we identify any VSMCc in preparations derived from the vascular stria or the spiral ligament. These findings confirm investigations with fixed specimen of the spiral ligament (Schicker, 1958; Iurato, 1962; Naumann, 1965; Hawkins et al., 1972; Kimura and Ota, 1974; Spoendlin, 1981) and strial microvessels (Rauch and Reale, 1968; Kimura and Schuhknecht, 1970; Kimura and Ota, 1974).

After permeabilization with saponin (Fig. 1a) and incubation with rhodamin-phalloidin VSMCs exhibited a bright red-orange fluorescence indicating the presence of F-actin underneath the cell membrane in the cytoplasm (Fig. 1b). Fluorescent phalloidin derivates have been established as highly specific visual markers for F-actin that mediates contractility and motility of VSMCs (Wieland, 1987).

\subsection{Endothelial cells}

Viable ECs were obtained from each of the three preparations, the spiral modiolar artery, the vascular stria and the spiral ligament. Diameter of single ECs was about 2 to $3 \mu \mathrm{m}$, irregardless of the vascular bed from which they werc derived (Fig. 2a). EC-clusters were of extremely various size and shape (ranging from 10 to 1000 cells).

Unlike enzyme treatment in order to isolate ECs from the spiral modiolar artery elastase and trypsin inhibitor was not required for dispersion of capillary ECs from the lateral wall tissue preparations. The capillary wall is composed of ECs and adjacent PCs, however they are not covered by an elastic layer and VSMCs. Therefore treatment with a commercial preparation of collagenase and dispase was adequate to obtain ECs from strial capillaries as described by Bowman et al. (1985). A more agressive treatment with higher dosis of collagenase in order to yield ECs from bovine spiral ligament as used by Bowman et al. (1985) was not required, since our preparations were incubated four times as long.

Shape and size of freshly isolated viable ECs are comparable to those observed in fixed tissue specimens using TEM. Kimura and Ota (1974) described the arterial wall of the spiral modiolar artery to be composed of ECs with a diameter of 2 to $4 \mu \mathrm{m}$. Direct information of the size of ECs in the vascular stria and the spiral ligament has not yet been provided. However, capillary diameter averages between $3.5 \mu \mathrm{m}$ (Axelsson, 1968) and $6.4 \mu \mathrm{m}$ (Kimura and Ota, 1974) in the stria and 4 to $5 \mu \mathrm{m}$ in the spiral ligament (Kimura and Ota, 1974). Therefore, the respective ECs should be of comparable size. Bowman et al. (1985) did not observe any significant differences in morphology of cultured ECs isolated from bovine capillaries of the stria and the spiral ligament.

Both single ECs and EC-cluster exhibited a brilliant orange fluorescence after incubation with DiI-Ac-LDL (Fig. 2b). Labeling of ECs with DiI-Ac-LDL seems the most reliable identification. Cultured ECs bind, internalize, and degrade LDL via receptor-mediated pathway (Vlodavsky et al., 1978) and it has been demonstrated that cultured bovine retinal as well as aortic ECs, but not cultured retinal PCs or VSMCs possess the scavanger pathway for Ac-LDL metabolism (Voyta et al., 1984; Tontsch and Bauer, 1989; Morse and Sidikaro, 1990). Other markers such as antibodies against factor VIII-related antigen or immunofluorescence staining for angiotensin-converting enzyme activity are not as uniformly effective and consistent compared to DiI-Ac-LDL (Voyta et al., 1984). In the present study with freshly isolated viable single ECs and EC-clusters we could confirm brilliant fluorescence as described in cultures of Dil-AC-LDL-labeled ECs obtained from non-cochlear vessels. Neither isolated PCs nor VSMCs exhibited any fluorescence after incubation with DiI-Ac-LDL.

\subsection{Pericytes}

Viable single PCs isolated from microvessels of the vascular stria were about $10 \mu \mathrm{m}$ in diameter. In many strial pericytes slender cell processes adhered to the cell surface. In contrast, isolated PCs from microvessels

\footnotetext{
Fig. 1. (a) Two vascular smooth muscle cells isolated from the spiral modiolar artery. The cells were permeabilized with the detergent Saponin as described in Material and Methods. Bar $10 \mu \mathrm{m}$. (b) Same cells as in Fig. 1a, stained for F-actin with rhodamine phalloidin after permeabilization with Saponin. Bar $10 \mu \mathrm{m}$.
}

Fig. 2. (a) Cluster of endothelial cells isolated from the microvcssels of the spiral ligament. Bar $10 \mu \mathrm{m}$. (b) Same cells as in Fig. $2 \mathrm{a}$, stained with DiI-Ac-LDL as described in Material and Methods. Bar $10 \mu \mathrm{m}$.

Fig. 3. (a) Pericyte isolated from the microvessels of the spiral ligament. Bar $10 \mu \mathrm{m}$. (b) Same cell as in Fig. 3a with immunofluorescently stained cell membrane. Bar $10 \mu \mathrm{m}$. 
of the spiral ligament did not show cell processes (Fig. $3 a$ ), and were somewhat larger in diameter (15 to 20 $\mu \mathrm{m})$.

In order to isolate viable single PCs from cochlear capillaries of the lateral wall tissue dosis and enzyme mixture used for isolation of ECs from these preparations was not changed.

PCs have been described in fixed tissue specimen adjacent to strial capillaries (Rauch and Reale, 1968; Kimuara and Schuknecht, 1970; Kimura and Ota, 1974; Sakagami et al., 1982; Anniko and Bagger-Sjöbäck, 1984), adhering to the microvessels in the spiral ligament (Schicker, 1958; Axelsson and Vertes, 1978; Kimura and Ota, 1974; Sakagami et al., 1982; Watanabe, 1986) and spiral prominence (Axelsson, 1968, v. Ilberg et al., 1968). However, quantitative data are not available from these studies.

After immunofluorescent labeling, the cell membrane of PCs was stained bright red, irrespective of the vascular bed from which they were isolated (Fig. 3b). The mAb $3 G 5$ antibody is highly specific for PCs. It will specifically bind to a glycolipid antigen on the cell surface of microvascular calf retinal pericytes (Nayak et al., 1988) and human brain pericytes (Schlingemann et al., 1990). In the present study we could confirm the expression of this antigen in PCs derived from the guinea pig cochlear microvessels of the vascular stria and of the spiral ligament. In contrast, ECs and VSMCs did not exhibit any fluorescence using this immunofluorescent labeling.

Freshly isolated single PCs did not exhibit the typical orange-red fluorescence of $\mathrm{F}$-actin as observed in VSMCs. In contrast, several studies of cultured PCs from noncochlear tissues have indicated the presence of actin (Kelley et al., 1987; DeNofrio et al., 1989; Sims, 1986; DeNofrio et al., 1989; Buchanan and Wagner, 1990; Diaz-Flores et al., 1991; Tilton, 1991 and Nehls and Drenckhahn, 1993). However, expression of F-actin in cultured cells may be related to the development of stress fibers which permii these cells to attach to the substratum of culture flasks (Darnell et al., 1990). Furthermore, while alpha-smooth muscle actin was seen inconsistently in cultures of bovine retinal PCs, it was absent from these cells in situ (Nehls and Drenckhahn, 1993).

\subsection{Viability}

The BCECF fluorescein derivates are widely used as intracellular fluorescent $\mathrm{pH}$ indicators, but also as a marker of cell membrane integrity and hence, for cell viability. The membrane permeant BCECF-AM is loaded into cells and hydrolized to the fluorescent tetracarboxylic acid by cytoplasmic esterases. The fluorescent acid accumulates in viable cells since it cannot traverse intact membranes as a polar compound. The cells therefore exhibit green fluorescence $(520-560 \mathrm{~nm})$ when excited by blue light $(450-490 \mathrm{~nm})$.

Viability scores of EC-clusters isolated from the spiral modiolar artery, the spiral ligament and the stria vascularis did not differ from each other. After isolation, $65 \% \pm 12 \%$ of EC-clusters were viable which may reflect a greater sensitivity to enzymatic or mechanical treatment. In this context, it is interesting to note that approximately $30 \%$ of EC-clusters did not exhibit the bright red fluorescence after incubation with DiI-AcLDL. Internalization of this ligand requires energy and intracellular degradation (Darnell et al., 1990). Our results imply that only viable ECs will stain with Di-AcLDL. The viability of VSMCs obtained from the spiral modiolar artery was $95 \% \pm 3 \%$. After dual-staining with BCECF-AM and saponin plus rhodamin-phalloidin viability was maintained for $10-20 \mathrm{~min}$ and then lost due to the effect of saponin. PCs were viable at $78 \% \pm 6 \%$ after isolation and gradient centrifugation, irregardless of whether the cells were dual-stained immunofluorescently and with BCECF-AM or loaded with BCECF-AM only. The cell membrane of both viable and non-viable pericytes was fluorescently stained after incubation with pericyte-specific mAb 3G5 and RITC-IgM as the fluorescent detecting agent. From this observation we suggest that the epitope of the antigen $3 G 5$ is still recognized in nonviable pericytes. Percentage of viability of ECs, VSMCs and PCs before gradient centrifugation did not differ significantly from those values obtained after gradient centrifugation in isotonic solutions of Nycodenz ${ }^{\mathrm{R}}$.

\subsection{Density gradient centrifugation}

ECs isolated either from the spiral modiolar artery or from the vascular stria and spiral ligament migrated into the gradient fraction with the lowest density (1.04 to $1.06 \mathrm{~g} / \mathrm{ml})$. Single VSMCs from the spiral modiolar artery were found to collect in the next fraction (1.06 to $1.08 \mathrm{~g} / \mathrm{ml}$ ), and most of the VSMC-clusters consisting of more than 5 up to 50 cells migrated into the fraction with a density of 1.08 to $1.10 \mathrm{~g} / \mathrm{ml}$. PCs from strial capillaries collected within the fraction of 1.06 to $1.08 \mathrm{~g} / \mathrm{ml}$, and most of the PCs isolated from the spiral ligament were seen in the fraction of 1.08 to $1.10 \mathrm{~g} / \mathrm{ml}$. Red blood cells, polymorphogranulocytes, undigested tissue fragments and small pieces of modiolar bone, which could not be cleared off the proximal branches of the spiral modiolar artery were spun into the fraction with a density greater than $1.10 \mathrm{~g} / \mathrm{ml}$. Other cellular debris remained in the medium on top of the gradients.

The gradient medium Percoll ${ }^{\mathrm{R}}$ has been widely used for separating ECs from cerebral cell suspensions, as well as from microvessels from the lateral wall tissue of the bovine inner ear (Bowman et al., 1985). However, 
we were not successful in separation of ECs, PCs and VSMCs from one another using this gradient medium. The cells allways migrated into the same fraction, irregardless of densities which had been formed to obtain the gradient and irregardless of the centrifugation procedure. This may be due to the small gradient volume $(160 \mu \mathrm{l})$ of the microtubes $(5 \times 20 \mathrm{~mm})$ which had been used in our separation procedure in contrast to $10 \mathrm{ml}$ preformed Percoll gradients used by others. In consideration of the small amount of tissue microdissected from the cochlea and the relatively small volume of the mixed cell suspension obtained after enzymatic digestion we prefered the microtubes. The gradient medium Nycodenz ${ }^{\mathbf{R}}$ provided superior separation according to the buoyant densities of cochlear VSMCs, PCs and ECs.

\section{Conclusion}

With the microdissection and cell isolation techniques described in the present method paper it has now become possible to investigate distinct and identifiable viable cell types derived from various microvascular beds of the inner ear. These preparations lay the basis to examine local mechanisms involved in receptor-mediated vasomotion and regulation of cochlear blood flow. These studies will enhance the understanding of how these cells interact with hormones, plasma constituents, blood cells and drugs. Furthermore, investigations of transendothelial transport may provide insight into molecular processes related to vascular permeability at the blood-strial endothelium barrier and the blood-perilymph barrier. Such in-vitro investigations may not only contribute to the understanding of cochlear physiology and the pathogenesis of various cochlear disease processes, they also may be of great therapeutic interest.

\section{Acknowledgements}

This work was supported by National Institutes of Health grant DC 00078. The authors thank Josef M. Miller, Alfred L. Nuttall, Tom E. Carey, John McLaren, Yehoash Raphael, Don Coling and Sherry Crann (Kresge Hearing Research Institute, University of Michigan), John Ford (Howard Hughes Research Institute, University of Michigan), A. Lorris Betz (Dept. for Neuroscience, University of Michigan) and Wolfgang Arnold (Clinic for Otorhinolaryngology, Technical University of Munich) for precious innovations and generous support.

We would also like to give our special thank to Professor J.E. Hawkins Jr. for his enthusiasm about this project and his wisdom and refreshing comments.

\section{References}

Anniko, M. and Bagger-Sjöbäck, D. (1984) The Stria vascularis. In: I. Friedmann and J. Ballantyne (Eds.), Ultrastructural Atlas of the Inner Ear, Butterworths, London, pp. 184208.

Axelsson, A. (1968) The vascular anatomy of the cochlea in theguinea pig and in man. Acta Otolaryngol. Suppl. 243, 1-134.

Axelsson, A. and Vertes, D. (1978) Vascular histology of the guinea pig cochlea. Acta Otolaryngol. 85, 198-212.

Bowman, P.D., Rarey, K.E., Rogers, C. and Goldstein, G.W. (1985) Primary culture of capillary endothelial cells from the spiral ligament and stria vascularis of bovine inner ear. Retention of several enduthelial cell properties in vitro. Cell Tissue Res. 241, 479-486.

Buchanan, R.A. and Wagner, R.C. (1990) Associations between pericytes and capillary endothelium in the Eel Rete Mirabile. Microvasc. Res. 39, 60-76.

Darnell, J., Lodish, H. and Baltimore, D. (1990) Molecular Cell Biology. Scientific American Books Inc., Freeman and Company, New York.

DeNofrio, D., Hoock, T.C. and Herman, I.M. (1989) Functional sorting of actin isoforms in microvascular pericytes. J. Cell Biol. 109, 191-202.

Diaz-Flores, L., Gutiérrez, R., Varela, H., Rancel, N. and Valladares, F. (1991) Microvascular pericytes, a review of their morphological and functional characteristics. Histol. Histopathol. $6,269-286$.

Droogmans, G., Declerck, I. and Casteels, R. (1987) Effect of adrenergic agonists on $\mathrm{Ca}^{2+}$-channel currents in single vascular smooth muscle cells. Pflügers Arch. 409, 7-12.

Ford, T.C. and Rickwond, D. (1982) Formation of isntonic Nycodenz gradients for cell separations. Anal. Biochem. 124, 293-298.

Hawkins, J.E. Jr. (1968) Vascular patterns of the membraneous labyrinth. In: A. Graybiel (Ed.), Third symposium on the role of the vestibular organs in space exploration. NASA, Washington DC, pp. 241-258.

Hawkins, J.E. Jr., Johnsson, L.G. and Preston, R.E. (1972) Cochlear microvasculature in normal and damaged ears. Laryngoscope 82 , 1091-1104.

Hawkins, J.E. Jr. (1976) Microcirculation in the labyrinth. Arch. Otorhinolaryngol. 212, 241-250.

Ilberg, C. von, Spoendlin, H. and Vosteen, K.H. (1968) Die Ultrastruktur und Funktion des Sulcus spiralis externus und der Prominentia spiralis der Meerschweinchenschnecke. Darstellung mittels Thorotrast. Arch. Klin. Exp. Ohr-Nas-Kehlk-Heilk. 192, 124-136.

Iurato, S. (1962) Submicroscopic structure of the membrancous labyrinth. III. The supporting structure of Cortis' organ (basilar membrane, limbus spiralis und spiral ligament). Z. Zellforsch. Mikrosk. Anat. 56, 40-96.

Jahnke, K. (1980) The fine structure of the cochlear plexus. Arch. Otorhinolaryngol. 228, 155-161.

Kelley, C., D'Amore, P., Hechtman, H.B. and Shepro, D. (1987) Microvascular pericyte contractility in vitro, comparison with other cells of the microvascular wall. J. Cell. Biol. 104, 483-490.

Kimura, R.S. and Schuhknecht, H.F. (1970) The ultrastructure of the human stria vascularis. Part I. Acta Otolaryngol. 69, 415-427.

Kimura, R.S. and Ota, C.Y. (1974) Ultrastructure of the cochlear blood vessels. Acta Otolaryngol. 77, 231-250.

Lamm, K. (1992) Experimental studies on microcirculation and oygen supply in the cochlea. Habilitation, Technical University of Munich, Munich, pp. 1-245.

Lawrence, M. (1970) Circulation in the capillaries of the basilar membrane. Laryngoscope 80, 1364-1375.

Lawrence, M. and Clapper, M. (1973) Cine studies of organ of Corti blood supply. In: A.J.D. de Lorenzo (Ed.), Vascular Disorders in Hearing Defects. University Park Press, Baltimore, pp. 131-148. 
Maass, B. (1982) Inner ear blood flow. Anatomical-functional observations. HNO $30,355-364$

Morse, L.S. and Sidikaro, Y. (1990) Isolation and characterization of bovine choroidal microvessel endothelium and pericytes in culture. Curr. Eye Res. 9, 631-642.

Naumann, H.H. (1965) On the vessels of the inner ear. Bibl. Anat. 7. $55-63$.

Nayak, R.C., Berman, A.B., George, K.L., Eisenbarth, G.S. and King, G.L. (1988) A monoclonal antibody (3G5)-defined ganglioside antigen is expressed on the cell surface of microvascular pericytes. J. Exp. Med. 167, 1003-1015.

Nehls, V. and Drenckhahn, D. (1993) The versality of microvascular pericytes, from mesenchyme to smooth muscle? Histochemistry $99,1-12$.

Nomura, Y. and Hiraide, F. (1968) Cochlear blood vessel. A histochemical method of its demonstration. Arch. Utolaryngol. 104 313-317.

Rauch, S. and Reale, E. (1968) Die Pericyten (Rouget-Zellen) der Stria-vascularis-Gefäße. Arch. Klin. Exp. Ohr-Nas-Kehlk-Heilk. $192,82-90$

Rickwood, D., Ford, T. and Graham, J. (1982) Nycodenz, a new nonionic iodinated gradient medium. Anal. Biochem. 123, 23-31.

Ritter, K. (1974) Angioarchitecture and vasomotion in cochlear vessels. Experimental studies on topography, morphology and function of guinea pig vessels. Habilitation, University of Mainz, Mainz, pp. 1-134.

Sakagami, M., Matsunaga, T. and Hashimoto, P.H. (1982) Fine structure and permeability of capillaries in the stria vascularis and spiral ligament of the inner ear of the guinea pig. Cell Tissue Res. 226, 511-522.

Schicker, S. (1958) Zur Histologie der Gefäße des Ligamentum spirale. Arch. Ohr-Nas-Kehlk-Heilk. 173, 370-377.

Schlingemann, R.O., Rietveld, F.J.R., de Waal, R.M.W., Ferrone, S. and Ruiter, D.J. (1990) Expression of the high molecular weight melanoma-associated antigen by pericytes during angiogenesis in tumors and healing wounds. Am. J. Pathol. 136, 1393-1405.

Schwalbe, G. (1887) Ein Beitrag zur Kenntnis der
Zirkulationsverhältnisse in der Gehörschnecke. In: C. Ludwig (Ed.), Festschrift. Beiträge zur Physiologie. F.C.W. Vogel, Leipzig, pp. $200-220$.

Simard, J.M. (1991) Calcium channel currents in isolated smooth muscle cells from the hasilar artery of the guinea pig. Pfliigers Arch. 417, 528-536.

Sims, D.E. (1986) The pericytes - a review. Tissue Cell 18, 153-174

Smith, C.A. (1951) Capillary areas of the cochlea in the guinea pig. Laryngoscope 61, 1073-1095.

Smith, C.A. (1973) Vascular patterns of the membranous labyrinth. In: A.J.D. deLorenzo (Ed.) Vascular Disorders in Hearing Defects, University Park Press, Baltimore, pp. 1-21.

Spoendlin, H. (1981) Autonomic innervation of the inner ear. Adv. Otorhinolaryngol. 27, 1-13.

Tilton, R.G. (1991) Capillary pericytes, perspectives and future trends. J. Electron. Microsc. Techn. 19, 327-344.

Tontsch, U. and Bauer, H.C. (1989) Isolation, characterization and long term cultivation of porcine and murine cerebral capillary endothelial cells. Microvasc. Res. 37, 148-161.

Vlodavsky, I., Fielding, P.E., Fielding, C.J. and Gospodarowicz, D. (1978) Role of contact inhibition in the regulation of receptormediated uptake of low density lipoprotein in cultured vascular endothelial cells. Proc. Natl. Acad. Sci. USA 75, 356-360.

Voyta, J.C., Via, D.P., Butterfield. C.E. and Zetter, B.R. (1984) Identification and isolation of endothelial cells based on their increased uptake of acetylated-low density lipoprotein. J. Cell Biol. 99, 2034-2040.

Watanabe, K. (1986) Ultrastructural characteristics of capillaries entering and leaving the stria vascularis. Ann. Otol. Rhinol. Laryngol. 95, 309-312.

Wersäll, J., Densert, O. and Lundquist, P.G. (1973) Studies of fine structure of inner ear vessels. In: A.J.D. de Lorenzo (Ed.), Vascular Disorders in Hearing Defects. University Park Press, Baltimore, pp. 4376.

Wieland, T. (1987) 50 Jahre Phalloidin. Seine Entdeckung, Charakterisierung sowie gegenwärtige und zukünftige Anwendung in der Zellforschung. Naturwissenschaften 74, 367-373. 